\title{
Medição da eficiência de magistrados e de unidades judiciárias no Ceará, Brasil: o sistema Eficiência.jus
}

\author{
LEONEL GOIS LIMA OLIVEIRA \\ Escola Superior de Magistratura do Estado do Ceará (ESMEC), Fortaleza- CE, Brasil \\ José Marcelo MaIA NogueIRA \\ Escola Superior de Magistratura do Estado do Ceará (eSMEC), Fortaleza- CE, Brasil
}

Kátia Michelle Matos de Oliveira

Tribunal de Justiça do Estado do Ceará (TJCE), Fortaleza- CE, BRAsil

SÉrgio Mendes de Oliveira Filho

Escola Superior de Magistratura do Estado do Ceará (eSMEC), Fortaleza- CE, Brasil

\begin{abstract}
Resumo
Este trabalho teve por objetivo retratar as características do Eficiência.jus, um Sistema de Apoio à Decisão que permite medir a eficiência de unidades judiciárias e de magistrados. Tal sistema fundamenta-se na metodologia "Análise Envoltória de Dados" (DEA). O Eficiência.jus foi desenvolvido no intuito de produzir informações estatisticamente tratadas que visem auxiliar a tomada de decisões dos gestores e servir como um suporte objetivo nas promoções das carreiras dos juízes estaduais. Em meio à caracterização do sistema, promove-se uma discussão focada nas dificuldades gerenciais encontradas quando de sua concepção e desenvolvimento. Enfatiza-se, também, as condições organizacionais básicas exigidas para seu funcionamento pleno.
\end{abstract}

Palavras-chave: Eficiência. Gestão do Judiciário. Magistrados. Sistema de Apoio à Decisão. Análise Envoltória de Dados.

Gauging the efficiency of magistrates and of judicial courts in the state of Ceará, Brazil: the system of Eficiência.jus

\section{Abstract}

This paper aims to outline the characteristics of Eficiência.jus, a Decision-making Support System for gauging the efficiency of judicial courts and magistrates. This system is based on the methodology known as "Data Envelopment Analysis" (DEA). The Eficiência.jus system was developed in order to produce statistically analyzed information aimed at helping the decision-making process of managers and to serve as objective support for promotion in the careers of state judges. While characterizing the system, the paper also promotes a discussion focused on the managerial difficulties encountered at the time of its conception and development. It also emphasizes the basic organizational conditions required for it to be fully operational.

Keywords: Efficiency. Court Management. Magistrates. Decision-making Support System. Data Envelopment Analysis.

Medición de la eficiencia de los magistrados y de las unidades judiciales en Ceará, Brasil: El sistema Eficiência.jus

\section{Resumen}

Este estudio tuvo como objetivo retratar Eficiência.jus que cuenta con un Sistema de Soporte de Decisiones para medir la eficiencia de las unidades judiciales y magistrados. Dicho sistema se basa en la metodología de "análisis envolvente de datos" (DEA). El Eficiência.jus fue desarrollado con el fin de producir informaciones tratadas estadísticamente destinadas a ayudar a la toma de decisiones de los administradores y servir como una orden de mantenimiento en las promociones de las carreras de los jueces estatales. En medio de la caracterización del sistema, se promueve un debate centrado en las dificultades de gestión encontradas cuando de su diseño y desarrollo. Se pone énfasis, también, en las condiciones básicas de organización para su pleno funcionamiento.

Palabras Clave: Eficiencia. Gestión de la Judicatura. Magistrados. Sistema de Soporte de Decisiones. Analísis Envolvente de Datos. 


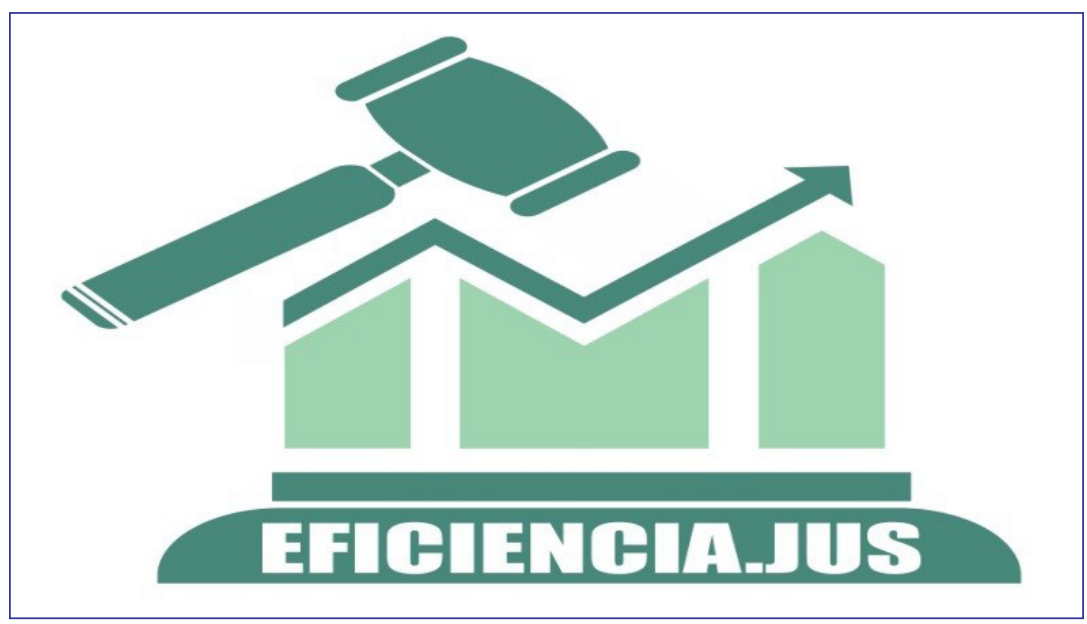

\section{INTRODUÇÃO}

O Poder Judiciário costuma ser taxado como moroso em sua atribuição de resolver conflitos sociais. Trata-se de uma percepção inversa do que se pode ser entendido como um "bom desempenho" ou, especificamente sobre uma prestação jurisdicional mais eficiente. Há, porém, perspectivas de mudanças com relação à melhoria do desempenho judicial que vêm sendo evidenciadas após a instalação do Conselho Nacional de Justiça (CNJ), órgão criado pela Emenda Constitucional (EC) 45/2004. O órgão surge com o objetivo principal de exercer controle administrativo e financeiro do Poder Judiciário brasileiro. Desse modo, ao longo dos últimos anos, o CNJ vem buscando elevar o nível de eficiência dos tribunais por meio de distintos instrumentos de gestão como, por exemplo, planejamento estratégico, metas, mensuração de desempenho, resoluções e recomendações nacionais.

Os tribunais têm procurado se adequar a esse movimento gerencial na busca de atender às regulamentações elaboradas pelo CNJ. Presume-se que os caminhos percorridos pelos tribunais são diferentes entre si, mas a falta de estudos sobre a Gestão do Judiciário, conforme apontado por Nogueira (2011), vem prejudicando a obtenção de maiores evidências que poderiam contribuir no entendimento e análise desse cenário. Por outro lado, ao analisar um caso no âmbito estadual do Judiciário brasileiro, Meireles (2012) procura demonstrar os esforços realizados pelo Tribunal de Justiça do Estado do Ceará (TJCE) para a obtenção de um sistema de apoio à decisão (SAD), denominado Eficiência.Jus. Este sistema busca oferecer uma análise da eficiência das unidades judiciais administradas pelo citado órgão. A busca pela eficiência é algo recorrente no movimento gerencial pelo qual passa todo o Poder Judiciário brasileiro (DPJ, 2012; DPJ, 2013).

O sistema foi desenvolvido pelo TJCE, em parceria com o Instituto de Estudos, Pesquisas e Projetos da Universidade Estadual do Ceará (IEPRO/UECE), no intuito de produzir informações tratadas estatisticamente que visem auxiliar a tomada de decisão dos dirigentes do judiciário cearense e também servir como um suporte objetivo nos processos de promoções das carreiras dos juízes estaduais. O Eficiência.Jus foi fundamentado na metodologia matemática denominada "Análise Envoltória de Dados" (Data Envelopment Analysis - DEA), onde se propõe a ordenar a eficiência relativa das unidades judiciais e dos magistrados.

O presente trabalho tem por objetivo retratar as principais características quanto à medição da eficiência de unidades judiciais (secretarias de vara) e de magistrados através do sistema Eficiência.jus. Este sistema já foi abordado por Meireles (2012) quando apresentou as etapas de estruturação em termos de programação do software. Porém, verificam-se limitações quanto

* Fonte da imagem: elaborado pelos autores. 
aos aspectos práticos e operacionais de como o sistema tem sido utilizado para a melhoria da gestão judiciária pelo TJCE. Deste modo, o presente estudo procura redimir estas lacunas com o uso de metodologia de caráter exploratório e descritivo, uma vez que apresenta detalhes sequenciais de como o sistema vem sendo colocado em prática no TJCE. Portanto, procura responder aos seguintes questionamentos: De que maneira o sistema Eficiência.jus mensura o desempenho dos magistrados e das unidades judiciais? Quais as implicações em adotá-lo como um instrumento de gestão no tribunal?

Primeiramente, apresentam-se as variáveis utilizadas no sistema Eficiência.jus. Em seguida, os procedimentos de análises procuram demonstrar os passos percorridos pelo desenvolvimento do sistema na busca de efetuar a mensuração dos níveis de eficiências das unidades e dos magistrados atuantes no judiciário cearense. Para a análise procedida neste estudo, foram utilizados dados de produtividade judicial relativos ao período posterior ao ano de 2009 até dezembro de 2011 , a fim de exemplificar como o sistema vem sendo desenvolvido para servir como ferramenta de tomada de decisão e, também, no auxílio da definição de critérios objetivos para a promoção dos magistrados.

Este trabalho está, portanto, estruturado da seguinte forma: a seção 2 apresenta uma breve descrição da Análise Envoltória de Dados (DEA). A seção 3 procura os procedimentos adotados quanto à análise da eficiência de magistrados. A seção 4 refere-se às possíveis interferências políticas, apresentando as limitações e méritos das atuais abordagens. Por fim, são apresentadas as considerações finais na Seção 5.

\section{ANÁLISE ENVOLTÓRIA DE DADOS (DEA)}

O cálculo da eficiência de uma unidade produtiva é utilizado na teoria econômica como forma de expressar a relação numérica existente entre os produtos obtidos e os recursos usados por uma determinada organização. Nesse contexto, o processo produtivo é caracterizado por atividades que utilizam uma dada quantidade de insumos para produzir uma determinada quantidade de produtos. Estas considerações são as bases para a fundamentação dos estudos voltados para a mensuração de eficiência. Os estudos de Charnes, Cooper e Rhodes (1978) e Cooper, Seiford e Tone (2007) serviram para consolidar os procedimentos de Análise Envoltória de Dados, utilizando processos que permitiam trabalhar com múltiplos insumos e múltiplos produtos na obtenção de indicadores de eficiência. Essa foi a origem da técnica de construção de fronteiras de produção e indicadores da eficiência produtiva conhecida como Análise Envoltória de Dados ou Data Envelopment Analysis (DEA) (NOGUEIRA, OLIVEIRA, VASCONCELOS et al., 2012).

A DEA como técnica foi utilizada inicialmente para estudos do Judiciário em 1982, ganhando destaque por permitir a comparação de coeficientes de eficiência relativa entre diferentes unidades. No caso, ao verificar a eficiência dos tribunais, a DEA mostrou-se adequada a estudos que focassem na medição da eficiência e do desempenho do Judiciário (LEWIN, MOREY e COOK, 1982). Este estudo serviu como referência para a realização de algumas outras pesquisas que podem ser encontradas na literatura internacional como, por exemplo, os trabalhos de Pedraja-Chaparro e Salinas-Jimenez (1996) no Judiciário espanhol, Sverre e Kittelsen (1992) na justiça norueguesa, Mitsopoulos e Pelagidis (2007) nas cortes judiciais gregas, Beenstock e Haitovsky (2004) e Gorman e Ruggiero (2009) no judiciário estadunidense.

Por sua vez, o Poder Judiciário brasileiro sempre careceu de mecanismos que permitissem um conhecimento mínimo de sua organização administrativa, o que findou por dificultar a realização de estudos semelhantes aos citados no contexto nacional. Até meados da década de 2000, era difícil conseguir responder de forma mais precisa alguns questionamentos básicos acerca de, por exemplo, quantidade de magistrados e/ou de servidores ativos no Brasil, quantidade de casos (processos) novos, a quantidade de casos finalizados, o orçamento dos tribunais, dentre outros dados elementares à administração de uma organização de médio/grande porte (SADEK, 2004; NOGUEIRA, OLIVEIRA, VASCONCELOS et al., 2012) tal qual o Poder Judiciário brasileiro. Na tentativa de tratar essa problemática, um movimento de coleta de dados gerenciais começou por diferentes frentes, desde a obtenção de dados mais agregados até dados mais individualizados, bem como a identificação dos maiores demandados da prestação jurisdicional (chamados tecnicamente como litigantes).

A partir de 2006, o CNJ passa a recolher e sistematizar dados estatísticos referentes a aspectos ligados ao desempenho das organizações judiciárias brasileiras. Os dados, após tratamento estatístico, passaram a ser apresentados em forma de indicadores agrupados em áreas como: insumos, dotações orçamentárias, litigiosidade e acesso à justiça (CNJ, 2006). Estes dados 
são divulgados por intermédio do relatório anual intitulado Justiça em Números. Os dados apresentados são considerados agregados, pois retrata a situação consolidada dos tribunais. Há subdivisões por competência e jurisdição ainda em nível macro (2ำ Grau; 1으 Grau; Turmas Recursais e Juizados Especiais), mas mesmo assim os dados não refletem a situação de segmentos específicos da justiça (como o segmento penal, civil, da fazenda pública, de família etc.) ou das unidades judiciárias de forma isolada (DPJ, 2012; DPJ, 2013).

A recomendação pela efetuação de estudos com o DEA na Administração Pública foi proposta detalhadamente por Peña (2008). No caso do Judiciário brasileiro, os dados coletados pelo relatório Justiça em Número permitiram a realização, no cenário nacional, de estudos que adotaram a DEA para avaliação da eficiência dos tribunais estaduais conforme vistos nos trabalhos de Fochezzato (2010), Yeung (2010), Yeung e Azevedo (2011) e, mais recentemente, em Nogueira et al. (2012). A adoção do DEA por parte da academia serviu como referência para a utilização desta metodologia por parte do CNJ. A edição de 2012 do relatório Justiça em Números realizou um trabalho preliminar ao utilizar a DEA na medição da eficiência dos Tribunais de Justiças estaduais (TJs) e dos Tribunais Regionais do Trabalho (TRTs) (DPJ, 2012). No entanto, na edição de 2013 foi oficialmente criado o Índice de Produtividade Comparada (IPC-JUS). Este se utiliza da DEA, classificando os tribunais de forma agrupada conforme o porte e o volume de demanda processual (DPJ, 2013).

A orientação pela eficiência tem sido evidenciada no levantamento de estudos sobre a medição do desempenho organizacional no Judiciário. A dimensão de eficiência foi apresentada em cerca de $94 \%$ dos estudos, destacando o indicador que se refere à taxa de resolução de processos. As outras dimensões encontradas foram: celeridade, independência, efetividade, acesso à Justiça e qualidade (GOMES e GUIMARÃES, 2013).

De forma complementar, os aspectos de avaliação de desempenho também podem ser visualizados em nível micro, no caso da avaliação da produção dos magistrados. Tal enfoque foi apontado nos estudos de Castro (2011) e na publicação do Departamento de Pesquisas Judiciárias (DPJ) do CNJ sobre avaliação do desempenho judicial (DPJ, 2011). Desta forma, o enfoque de estudos nos magistrados apresenta-se como o ponto de partida para o aprofundamento na análise da eficiência de magistrados com o sistema Eficiência.jus.

\section{ANÁLISE DA EFICIÊNCIA DE MAGISTRADOS}

O processo de desenvolvimento do sistema Eficiência.jus iniciou-se com o estudo dos principais aspectos que envolvem a análise da eficiência dos magistrados em termos quantitativos. Em linhas gerais, tal análise parte de ponderações acerca das variáveis a serem utilizadas, bem como de aspectos relacionados com as competências das unidades judiciais tomadas para estudo. Os subitens que seguem tratam de expor o roteiro adotado.

\section{Variáveis e Competências}

O ponto de partida para a análise da eficiência dos magistrados foi a escolha das variáveis, as quais deveriam retratar tanto suas produtividades, quanto os recursos e a estrutura de que dispunham no desempenho de suas atividades. Para tanto, optou-se por utilizar como base os parâmetros estabelecidos no art. 6o da Resolução no 106/2010 do CNJ (CNJ, 2010), que dispõe sobre os critérios a serem observados para aferição da produtividade nas promoções e acessos de magistrados aos tribunais de $2 \circ$ grau, a saber:

Art. 6ㅇ Na avaliação da produtividade serão considerados os atos praticados pelo magistrado no exercício profissional, levando-se em conta os seguintes parâmetros:

I - Estrutura de trabalho, tais como:

a) compartilhamento das atividades na unidade jurisdicional com outro magistrado (titular, substituto ou auxiliar);

b) acervo e fluxo processual existente na unidade jurisdicional;

c) cumulação de atividades;

d) competência e tipo do juízo; 
e) estrutura de funcionamento da vara (recursos humanos, tecnologia, instalações físicas, recursos materiais);

II - Volume de produção, mensurado pelo:

a) número de audiências realizadas;

b) número de conciliações realizadas;

c) número de decisões interlocutórias proferidas;

d) número de sentenças proferidas, por classe processual e com priorização dos processos mais antigos;

e) número de acórdãos e decisões proferidas em substituição ou auxílio no 2o grau, bem como em Turmas Recursais dos Juizados Especiais Cíveis e Criminais;

f) o tempo médio do processo na Vara.

Neste sentido, o cálculo das eficiências tomou como base o framework exposto na Quadro 1. A competência e o tipo do juízo, contidos na alínea "d" do inciso I, referente à estrutura de trabalho, foram observados na escolha dos nichos de comparação para fins de cálculo das eficiências relativas. No sistema Eficiência.jus, cada magistrado é comparado apenas com os juízes que atuaram na mesma competência e natureza judicial, no mês de referência do cálculo.

\section{Quadro 1}

Variáveis utilizadas para o cálculo de eficiência

\begin{tabular}{|c|c|c|}
\hline SIGLA & DESCRIÇÃO DA VARIÁVEL & TIPO \\
\hline CNCrim & Casos Não Criminais & INPUT \\
\hline CCrim & Casos Criminais & INPUT \\
\hline PNCrim & Precatórias Não Criminais & INPUT \\
\hline PCrim & Precatórias Criminais & INPUT \\
\hline num_func & № de Funcionários do Quadro Efetivo & INPUT \\
\hline num_colab & № de Colaboradores (terceirizados, estagiários e comissionados) & INPUT \\
\hline num_comp & № de Computadores & INPUT \\
\hline Des & Despachos & OUTPUT \\
\hline Pdev & Precatórias Devolvidas & OUTPUT \\
\hline Sent & Sentenças & OUTPUT \\
\hline Aud & Audiências & OUTPUT \\
\hline Dint & Decisões Interlocutórias & OUTPUT \\
\hline num_unid & № de Unidades que atuou no mês & OUTPUT \\
\hline num_Conc & Número de Conciliações Realizadas & OUTPUT \\
\hline AtivCum & № de Atividades Cumuladas & OUTPUT \\
\hline
\end{tabular}

Fonte: TJCE, 2010b.

Com essa medida pretendeu-se efetuar comparações isonômicas entre magistrados que atuam em competências com trâmites e ritos processuais distintos. Do contrário, certamente gerariam análises superficiais e distorcidas, tendo em vista que variáveis, como número de audiências, sentenças, conciliações e decisões interlocutórias, possuem características particulares, a depender da natureza dos processos que as originem.

Tal fato pode ser facilmente constatado a partir de uma simples observação do quantitativo de audiências, por exemplo, em uma Vara da Fazenda Pública e em uma Vara Criminal, cujos números, por si só, sem a consideração das especificidades 
intrínsecas de cada competência, poderiam induzir ao equívoco de se concluir que um magistrado atuante numa Vara Criminal seria mais produtivo do que um magistrado da Fazenda Pública, no que se refere ao número de audiências realizadas por mês, quando na realidade é o próprio processo criminal que exige uma maior frequência de audiências a serem realizadas. Em contrapartida, ao se comparar apenas os juízes da mesma competência, como juízes criminais entre si, garante-se que o índice de eficiência relativa calculado refletirá o desempenho líquido de cada magistrado, a partir das suas capacidades individuais.

As competências, por sua vez, foram definidas a partir de minucioso estudo dos normativos que disciplinam as Secretarias de Vara do 1 으 grau cearense, do qual se pode identificar 53 agrupamentos de unidades com maior similaridade funcional. Os normativos que regraram a construção das citadas competências foram:

- Lei no 14.407/2009 - Código de Divisão e Organização Judiciária do Estado do Ceará (CEARÁ, 2009);

- Resolução no 18/2009 (TJCE, 2009);

- Resolução no 07/2010 (TJCE, 2010a);

- Resolução no 10/2010 (TJCE, 2010b);

- Resolução no 12/2010 (TJCE, 2010c);

- Resolução no 05/2011 (TJCE, 2011).

\section{Tratamento de Variáveis de Insumo}

Para que fosse feita uma aproximação das análises de eficiência da realidade do Poder Judiciário e dos magistrados, foi necessário o desenvolvimento de tratamentos matemáticos que permitissem contemplar, de forma isonômica, o trânsito de juízes para atendimento em várias unidades e a divisão de acervos processuais entre os mesmos. Tais tratamentos podem ser entendidos como algoritmos que, em situações específicas, tratam de maneira diferenciada as variáveis, de forma a sanar as distorções que resultariam da sua utilização direta. O funcionamento de cada algoritmo será detalhado nas subseções seguintes, bem como seus resultados.

\section{Algoritmo do Acervo Processual}

No Poder Judiciário são frequentes os casos em que magistrados precisam atuar em mais de uma unidade simultaneamente. Geralmente atuam em decorrência da vacância de cargos de juízes outrora titulares, ou por afastamentos temporários destes, ou mesmo a bem do serviço público, prestando auxílio em determinas áreas mais demandadas. Em casos como estes, a simples consideração das variáveis relacionadas ao acervo processual (casos criminais, casos não criminais, precatórias criminais e precatórias não criminais) de todas as unidades em que o magistrado estivesse atuando poderia lhe trazer prejuízo significativo em termos de eficiência. Desta forma, o somatório dos insumos estaria em descompasso com sua produção no período, a qual não sofreria o mesmo efeito multiplicativo e apenas seria dividida entre as unidades em que o mesmo atuou.

O algoritmo do acervo busca, portanto, sanar tal distorção ao calcular o acervo do juiz de forma proporcional ao número de unidades em que o mesmo trabalhou no mês e de acordo com sua forma de atuação em cada uma delas. Em outras palavras, se o juiz atua como titular da unidade, como auxiliar ou se respondendo temporariamente, no caso da ausência do titular.

Para melhor entendimento do funcionamento do algoritmo, parte-se do caso de uma unidade judiciária X, na qual atuaram, ao longo de um determinado mês, o seu juiz titular, um juiz auxiliar e um juiz respondendo. Admite-se ainda, por hipótese, que nenhum dos três magistrados atuou em outra unidade naquele mês, seja auxiliando, respondendo, ou como titular. $A$ ideia básica do algoritmo, para esse caso, é que cada juiz deva assumir uma parte do acervo da unidade, de forma que cada um teria, nesta unidade, como insumo processual, o resultado do seguinte cálculo:

$$
\text { Acervo Parcial do Juiz na Unidade } \mathrm{X}=\frac{\text { Acervo da Unidade } X}{N^{o} \text { de Juízes na Unidade } X}
$$

Relaxando a hipótese de atuação exclusiva, considere-se, agora, que um desses juízes atuou e dividiu o acervo em outras unidades. Nesse novo contexto, a simples soma dos seus acervos parciais ainda lhe seria prejudicial, posto que, como dito 
anteriormente, ele teve de dividir sua produção dentre todas as unidades em que trabalhou. Em contrapartida, o algoritmo calcula seu acervo final no formato de acervo médio, o qual se aproximaria ao acervo de uma única unidade representativa, caso nela tivesse atuando de forma exclusiva:

$$
\text { Acervo Final do Juiz }=\frac{\text { Soma dos Acervos Parciais }}{N^{o} \text { de unidades em que atuou }}
$$

Contudo, na prática, a situação funcional do juiz nas unidades (titular, respondente ou auxiliar) também influencia seu grau de responsabilidade sobre os acervos, de forma que tais fatores são considerados no algoritmo da seguinte forma:

a) Juiz Titular: o magistrado já possui uma unidade sob sua responsabilidade permanente, nela devendo destacar maiores esforços e, ao atuar em outra unidade, fá-lo de forma meramente colaborativa, apenas contribuindo temporariamente. Por essa razão, e como forma de beneficiar o juiz titular que se disponibiliza a ajudar em outras unidades, o algoritmo não o inclui na divisão do acervo das unidades em que estiver respondendo ou auxiliando, sendo a ele adicionado, como insumo trazido destas unidades, apenas o quantitativo de processos referentes às sentenças em que nelas tiver proferido, ou seja, traz para sua análise "100\% de eficiência". Segue-se o exemplo da Figura 1:

Figura 1

Cálculo do Acervo do Juiz A

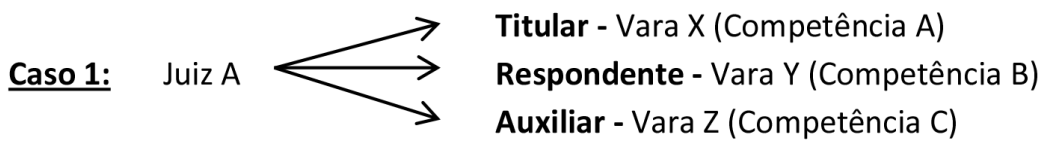

\section{Cálculo do Acervo do Juiz A:}

\begin{tabular}{lccc}
\hline & Vara X & Vara Y & Vara Z \\
\hline Acervo & 5.000 & 6.000 & 6.500 \\
\hline $\begin{array}{l}\text { Produção do juiz em } \\
\text { cada unidade }\end{array}$ & - & 160 & 170 \\
\hline
\end{tabular}

\section{Acervo Final do Juiz A: $5000+160+170=5330$}

\section{Eficiências Calculadas no mês para o Juiz A.}

- Eficiência na competência A (comparando apenas juízes das Varas pertencentes à Competência A)

Fonte: Elaborado pelos autores.

b) Juiz sem titularidade e com respondência: nesses casos, como o magistrado não possui um acervo permanente sob sua responsabilidade, o mesmo dividirá o acervo da unidade em que estiver respondendo, juntamente com os demais juízes que nela atuarem e que também devam entrar na divisão. Contudo, caso o magistrado esteja também auxiliando em alguma outra unidade, esta não entrará na divisão total do acervo, sendo a ele adicionado apenas o quantitativo de processos referentes às sentenças em que tiver proferido na unidade em que respondeu. Segue-se o exemplo da Figura 2: 
Figura 2

Cálculo do Acervo do Juiz B

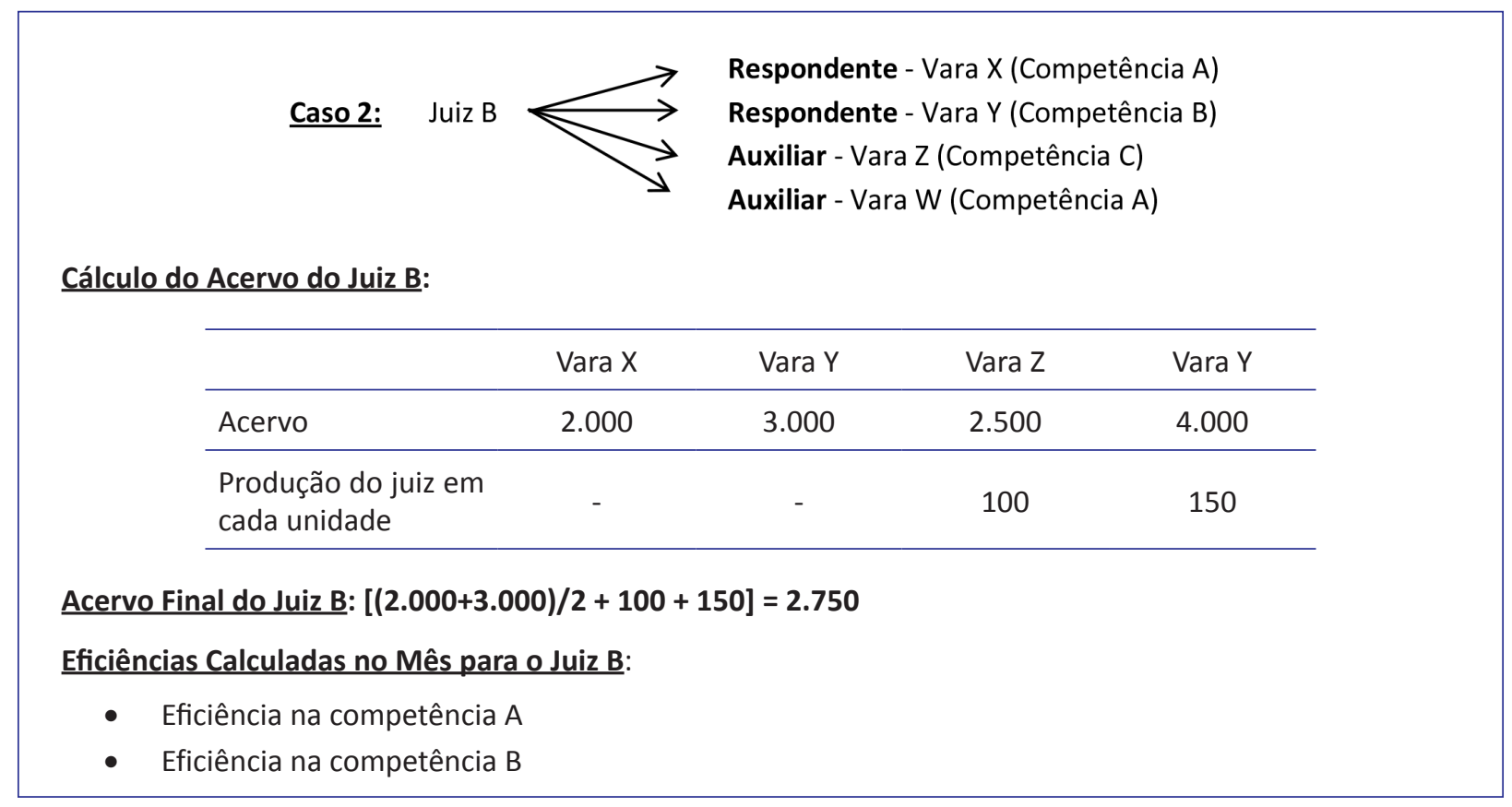

Fonte: Elaborado pelos autores.

c) Juiz auxiliando: neste último cenário, como o juiz não possui nenhum acervo sob sua titularidade ou respondência temporária, seu acervo final é calculado a partir da média dos acervos parciais obtidos em cada unidade em que estiver atuando. Segue-se o exemplo da Figura 3:

Figura 3

Cálculo do Acervo do Juiz C

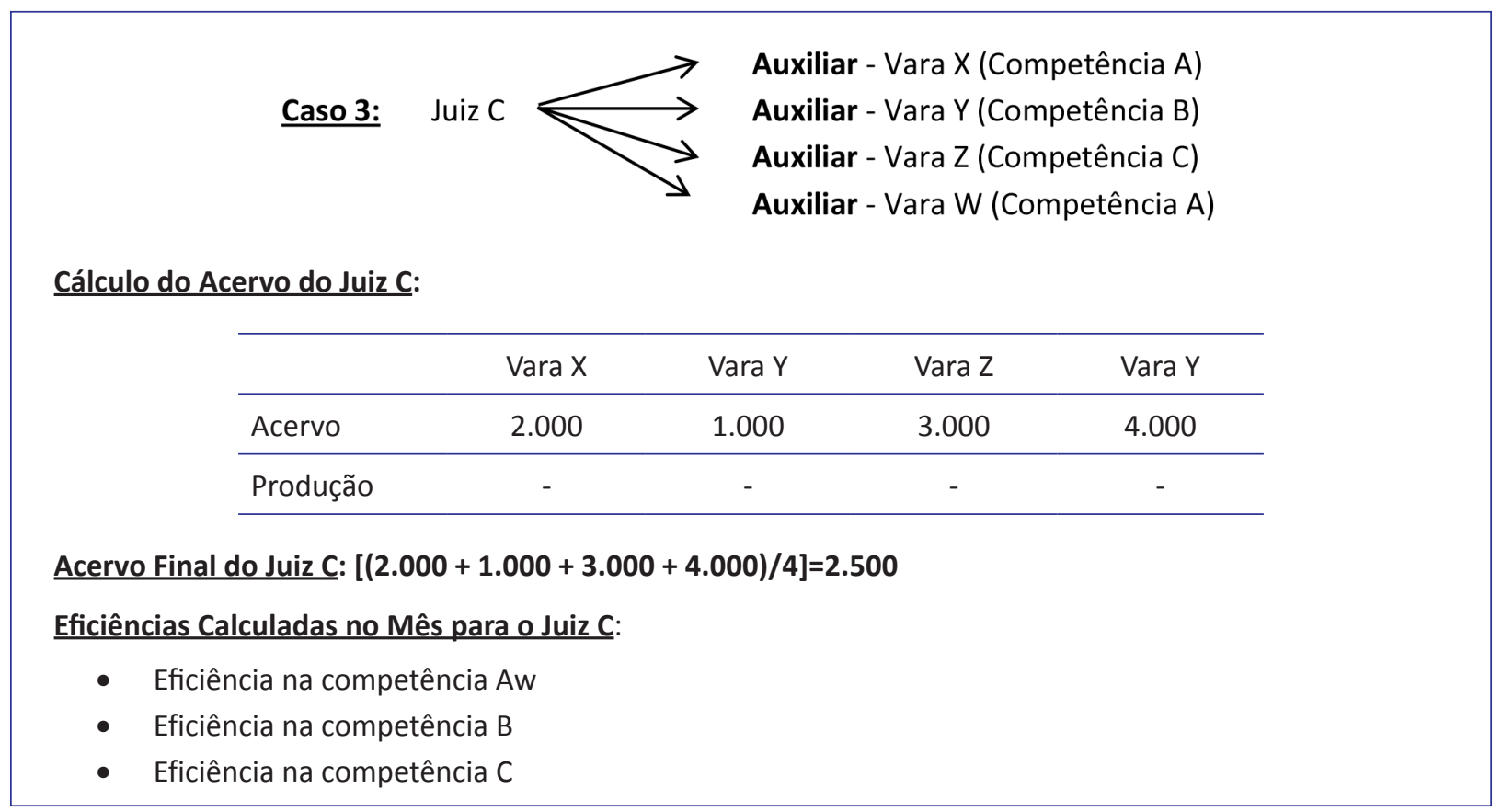

Fonte: Elaborado pelos autores. 
A partir destas regras, tem-se que o acervo de cada juiz é calculado pelo seguinte algoritmo:

1. Calculando os acervos parciais de cada juiz, em cada unidade judiciária, dividindo o acervo entre os juízes da unidade que devem entrar na divisão:

$$
A P_{i}=\left(\frac{A_{i}-P_{R T}-P_{A T}-P_{A R}}{N_{J D}}\right)
$$

Onde:

$A P_{i}=$ Acervo parcial do Juiz na Unid. Judiciária $i$

$A_{i}=$ Acervo Total da Unidade $i$

$P_{A T}=$ Produção total dos Juízes que são Auxiliares na Unidade $i$ e são

Titulares em outras

$P_{A R}=$ Produção total dos Juízes que são Auxiliares na Unidade $i$ e estão

Respondendo em outras

$N_{J D}=$ Número de Juízes que dividem o acervo na Unidade $i$

2. Tratando do caso em que juízes são titulares em alguma unidade judiciária, sendo seus acervos finais calculados a partir da seguinte fórmula:

$$
A F=\frac{\sum_{i=1}^{N_{U D}} A P_{i}}{N_{U D}}+P_{R}+P_{A}
$$

Onde:

$A F=$ Acervo final do juiz

$N_{U D}=\mathrm{N}^{\mathrm{o}}$ de Unidades Judiciárias onde o Juiz divide o acervo

$P_{R}=$ Produção total do Juiz como Respondente

$P_{A}=$ Produção total do Juiz como Auxiliar

3. Tratando do caso em que juízes estão respondendo em alguma unidade judiciária, mas que não são titulares em nenhuma outra, sendo seus acervos finais calculados a partir da seguinte fórmula:

$$
A F=\frac{\sum_{i=1}^{N_{U D}} A P_{i}}{N_{U D}}+P_{A}
$$

4. Calculando o acervo final dos juízes que não foram afetados pelos passos 2 e 3 como a média dos acervos parciais calculados:

$$
A F=\frac{\sum_{i=1}^{N_{U D}} A P_{i}}{N_{U D}}
$$

Vale ressaltar, finalmente, que, apesar de ter sido utilizado o termo genérico "acervo", os cálculos acima são efetuados para cada uma das variáveis relacionados ao estoque processual da unidade, ou seja, casos não criminais, casos criminais, precatórias não criminais e precatórias criminais. 


\section{Tratamento das Variáveis de Recursos Humanos e Infraestrutura}

Para consideração das variáveis relacionadas ao quadro funcional e à infraestrutura disponível em cada unidade também foi necessário um tratamento preliminar para se evitar distorções nas análises de eficiência. Contudo tal tratamento se mostra menos complexo, tendo em vista que a situação funcional do magistrado nas unidades não representa qualquer efeito sobre o número de servidores, colaboradores ou de computadores a ser considerado. Neste caso, leva em conta apenas o quantitativo de unidades em que o mesmo atuou.

Desta forma, caso o juiz tenha atuado em mais de uma unidade no mês de referência, o número de funcionários, colaboradores e de computadores que comporão o cálculo da sua eficiência, como insumos, serão dados pela média de cada variável.

$$
\begin{gathered}
\text { Num_func }=\frac{\sum_{i=1}^{N_{U D}} N u m_{-} \text {func }_{i}}{N_{U D}} \\
\text { Num_colab }=\frac{\sum_{i=1}^{N_{U D}} N u m_{-} \text {colab }_{i}}{N_{U D}} \\
N u m_{-} \text {comp }=\frac{\sum_{i=1}^{N_{U D}} N u m_{-} \text {comp }_{i}}{N_{U D}}
\end{gathered}
$$

Onde:

Num_ func $_{i}=$ Número de servidores efetivos da unidade judiciária $i$.

Num_colab ${ }_{i}=$ Número de ocupantes de cargos comissionados, estagiários e terceirizados da unidade judiciária $i$.

Num_comp $p_{i}=$ Número de computadores da unidade judiciária $i$.

\section{Tratamento de férias e afastamentos}

Observou-se, por fim, que nos meses em que se verificavam períodos fracionados de férias ou de afastamentos do magistrado, a eficiência relativa deste se mostrava subdimensionada e distorcida, uma vez que sua produção era parcial e a comparação se dava com magistrados que produziram de forma integral ao longo do mês em referência. Demais disso, apesar da sua produção ter sido reduzida, os insumos não se restringiam com o seu afastamento, de forma que a eficiência findava por retratar uma baixa relação "insumo-produto".

Desta forma, o algoritmo construído trata a situação da seguinte forma:

1. Caso o juiz tenha trabalhado menos de 15 dias no mês, desconsidera-se o período em referência, não sendo calculado índice de eficiência para o magistrado naquele mês;

2. Caso o juiz tenha trabalhado 15 dias ou mais, considera-se o mês em referência, contudo sua eficiência é calculada a partir de projeções das suas variáveis de produção. Estas partem da sua produção diária média e representam uma aproximação dos quantitativos que teriam sido atingidos, caso o magistrado tivesse trabalhado o mês integral, ou seja:

$$
V_{\text {Proję̧ão }}=\left(\frac{V_{\text {produção }}}{D_{T}}\right) \times 30
$$

Onde:

$V_{\text {Projeção }}=$ Projeção mensal da variável de produção (ex : sentenças)

$V_{\text {Produção }}=$ Valor da variável efetivamente produzido no mês

$D_{T}=$ Número de dias trabalhados pelo juiz 


\section{Informações geradas}

Além das soluções até aqui delineadas, sobretudo o fato de que as comparações procedidas consideram somente juízes da mesma natureza ou competência judicial, contemplando, tanto as tradicionais variáveis de produtividade (despachos, sentenças etc.), quanto os recursos disponíveis (estrutura da vara, número de funcionários e acervo processual), o Eficiência.jus disponibiliza, ainda, uma série de informações gerenciais, mediante gráficos de evolução e tabelas comparativas, os quais fornecem subsídios aos magistrados para gestão interna das suas unidades e da sua própria produção individual. Destaca-se que esta análise apresenta maior nível de profundidade do que o estudo de Castro (2011) e, também, vai ao encontro da ideia de avaliação do desempenho judicial (DPJ, 2011).

Como exemplo de informações tem-se:

- Evolução da eficiência do magistrado nos últimos 12 meses, comparado com a média (conforme Gráfico 1):

\section{Gráfico 1}

\section{Evolução da eficiência do(a) juiz(a) por competência}

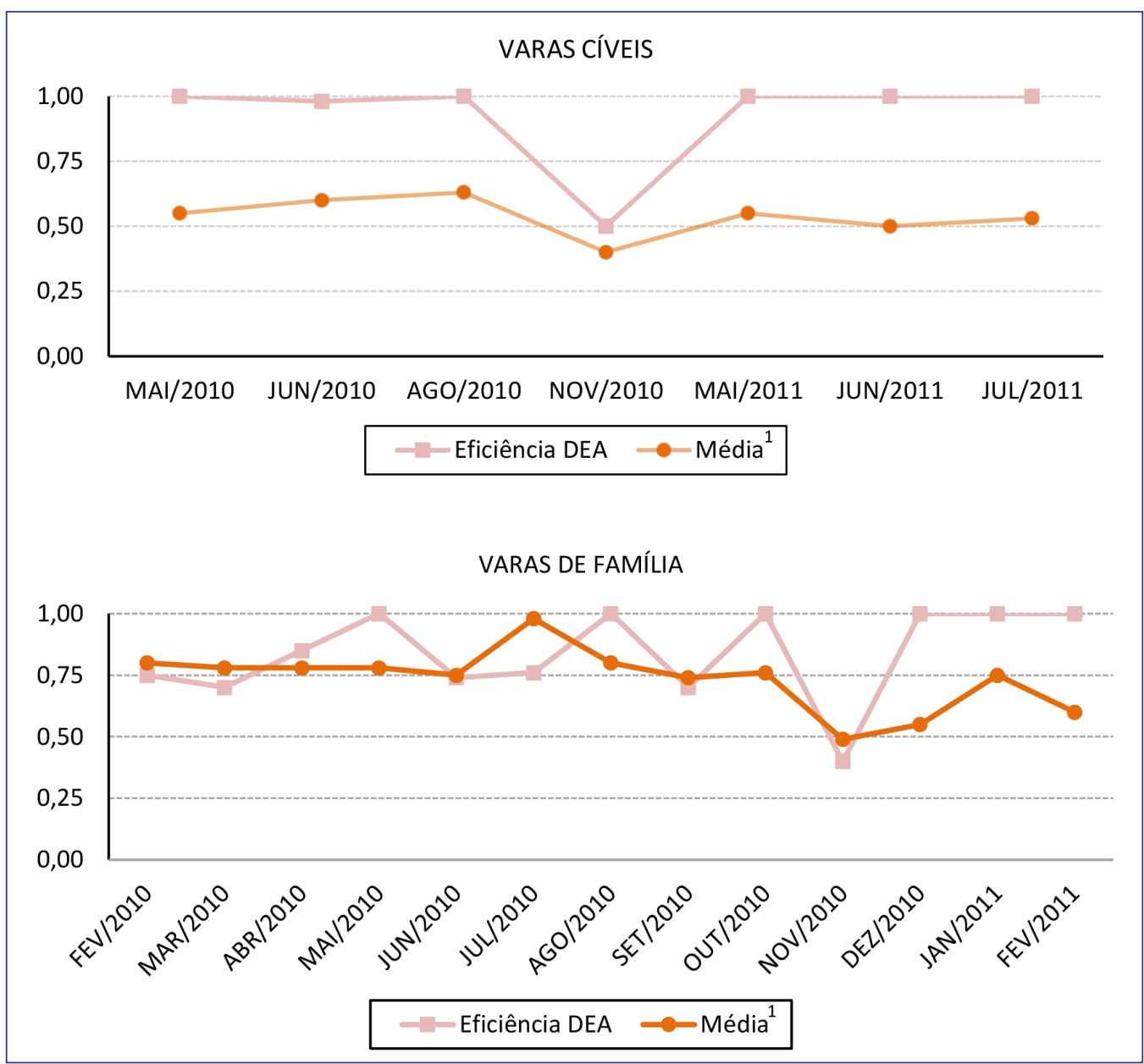

${ }^{1}$ Média das Eficiências dos Juízes (Varas Cíveis)

Fonte: Elaborado pelos autores e extraído do Eficiência.Jus.

Projeções mensais dos níveis ótimos de cada variável envolvida na análise da eficiência, calculadas a partir da análise envoltória de dados, as quais servem de norteamento ao magistrado do que ele deve melhorar e do quanto ele precisa incrementar sua produção para atingir índices maiores de eficiência (conforme Tabela 1): 
Tabela 1

Projeções do(a) juiz(a) por competências e por mês

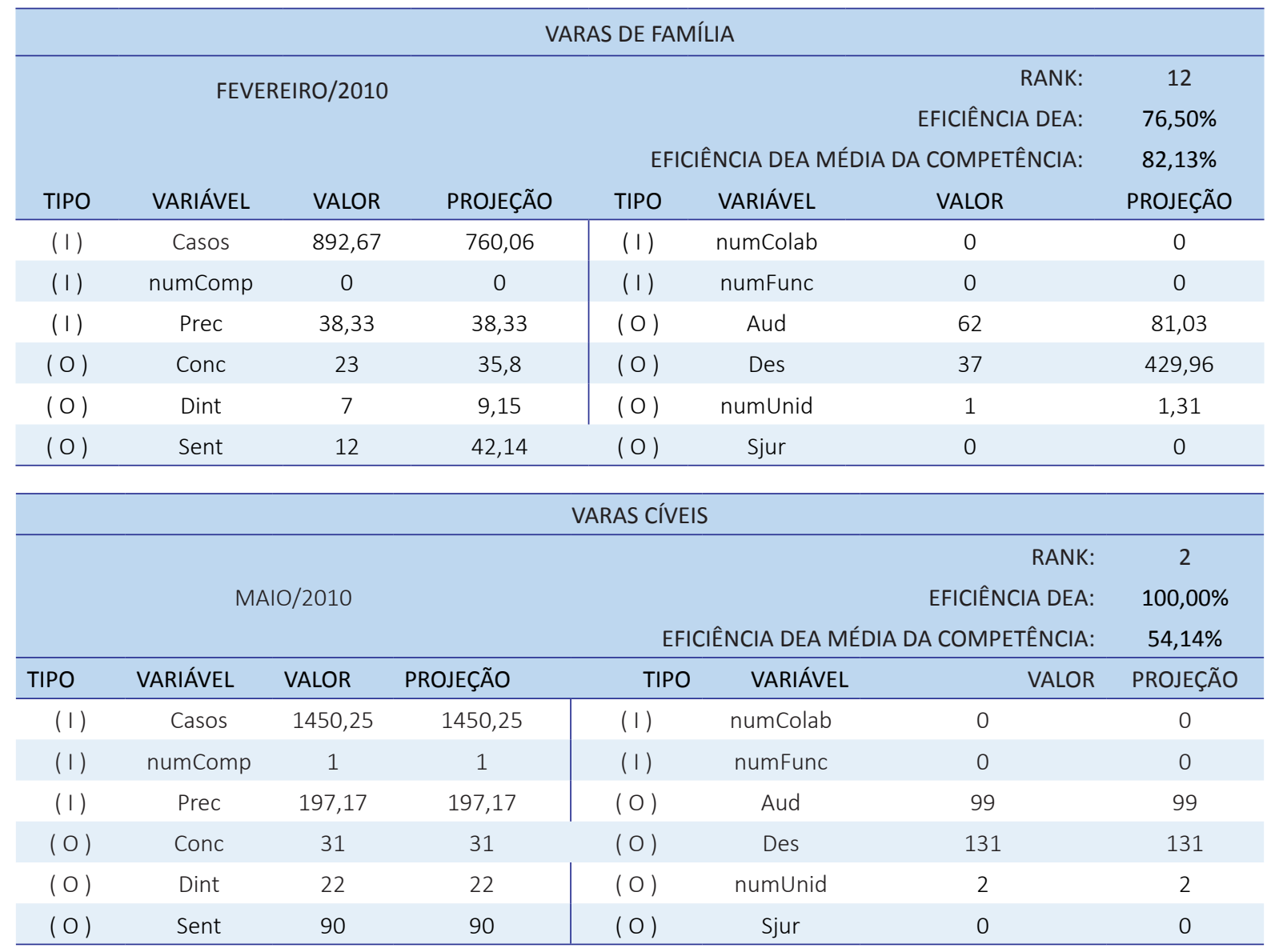

Fonte: Elaborado pelos autores e extraído do Eficiência.Jus.

- Ranking dos magistrados por competência, em termos de índices de eficiência alcançados (Tabela 2 e Gráfico 2):

Tabela 2

Eficiências dos Juízes de Varas Cíveis

\begin{tabular}{|c|c|c|}
\hline \multicolumn{3}{|c|}{ VARAS CÍVEIS } \\
\hline \multirow[t]{5}{*}{ JANEIRO/2010 } & Médias das Eficiências dos Juízes & $70,90 \%$ \\
\hline & Menor Valor das Eficiências dos juízes & $20,00 \%$ \\
\hline & Maior Valor das Eficiências dos juízes & $100,00 \%$ \\
\hline & Variâncias das Eficiências dos Juízes & $11,23 \%$ \\
\hline & Desvio Padrão das Eficiências dos Juízes & $33,51 \%$ \\
\hline
\end{tabular}

Fonte: Elaborado pelos autores e extraído do Eficiência.Jus. 
Gráfico 2

Ranking das eficiências médias dos juízes no período

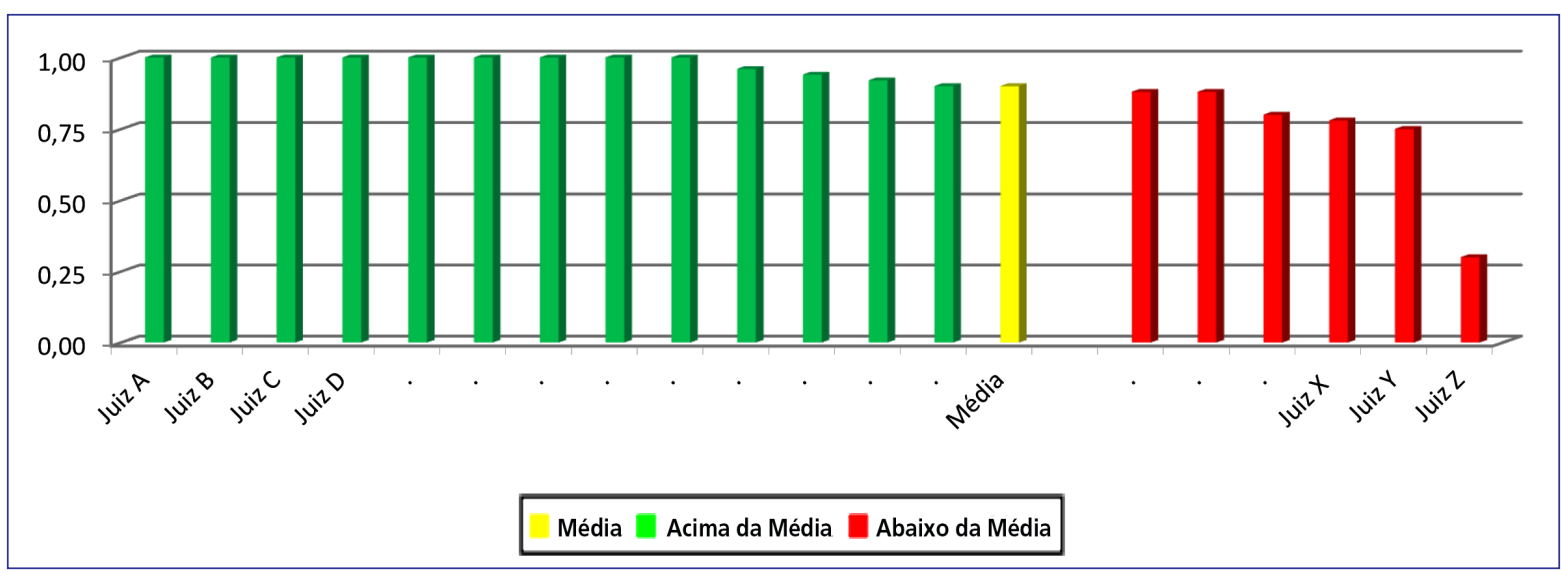

Fonte: Elaborado pelos autores e extraído do Eficiência.Jus.

\section{EFICIÊNCIA COMO CRITÉRIO DE PRODUTIVIDADE}

Esta seção busca retratar os aspectos que demonstram a eficiência como critério de produtividade (GOMES e GUIMARÃES, 2013). Serão apresentadas as operações realizadas para a promoção de magistrados, bem como a forma pela qual os dados são gerados pelo sistema Eficiência.jus.

\section{Promoção de magistrados}

A Resolução no 106/2010 do CNJ (CNJ, 2010) especifica, no §1으 do art. 4으, que, para a avaliação dos magistrados, deverão ser considerados os últimos 24 meses de efetivo exercício, e, em seu art. 11, que a pontuação máxima para o critério de produtividade é de 30 pontos num total de 100. Assim, os 70 pontos restantes referem-se a critérios de desempenho (aspecto qualitativo da prestação jurisdicional), presteza no exercício das funções, aperfeiçoamento técnico e adequação da conduta ao Código de Ética da Magistratura Nacional.

Para o uso do sistema, a análise de eficiência para efeito de promoção é realizada mensalmente, de forma que, ao término dos 24 meses de efetivo exercício, cada magistrado terá 24 índices de eficiência calculados, os quais servirão de base para a construção das pontuações referentes aos critérios de produtividade. Vale ressaltar, ainda, que, se durante um mês o magistrado tiver atuado em mais de uma competência, sua eficiência relativa é calculada em cada uma delas de forma isolada, considerando-se os algoritmos descritos nas seções anteriores.

O cálculo da pontuação, por sua vez, baseia-se no valor padronizado, que indica o quanto acima ou abaixo da média o magistrado está em termos de unidades padronizadas de desvio. Em outras palavras, mostra a posição de um magistrado em relação à média, dado o nível de variabilidade da competência.

Nesse sentido, para cada magistrado, em cada mês, e em cada competência que o mesmo tiver atuado, é calculado o valor padronizado da seguinte forma:

$$
V P=\frac{\text { Eficiência }- \text { média }}{D P}
$$


Em que:

$V P=$ valor padronizado do magistrado;

Eficiência = eficiência do magistrado no mês;

Média = média das eficiências dos magistrados da competência;

$D P=$ desvio padrão das eficiências da competência.

A partir deste cálculo, tem-se o quanto cada magistrado se distancia da média da competência em unidades de desvio padrão. A forma de cálculo da pontuação a partir do valor padrão poderá ser mais bem entendida através do exemplo que será descrito a seguir.

Suponha-se que o Juiz A teve sua eficiência calculada para o período de 02 meses. A Tabela 3 mostra os resultados de sua eficiência, a média e o desvio padrão da competência, bem como o valor padronizado e a pontuação.

\section{Tabela 3}

Resultados da eficiência do Juiz A

\begin{tabular}{|c|c|c|c|c|c|}
\hline 1a Competência & $\begin{array}{c}\text { Eficiência } \\
\text { (Juiz A) }\end{array}$ & $\begin{array}{c}\text { Média da } \\
\text { Competência }\end{array}$ & $\begin{array}{c}\text { Desvio } \\
\text { Padrão }\end{array}$ & $\begin{array}{c}\text { Valor } \\
\text { Padronizado }\end{array}$ & Pontuação \\
\hline Janeiro & $89 \%$ & $90,8 \%$ & 11,52 & $-0,156$ & 28 \\
\hline Fevereiro & $67 \%$ & $88 \%$ & 7,93 & $-1,730$ & 25 \\
\hline
\end{tabular}

Fonte: Elaborado pelos autores a partir dos dados da pesquisa.

Observe-se que a pontuação do juiz é calculada dentro de cada mês, sempre o comparando com o desempenho dos juízes da mesma competência. A pontuação é calculada por meio da seguinte normalização:

$$
P=30-2 \cdot\left(V P_{\text {Máx }}-V P_{\text {Juiz }}\right)
$$

Em que:

P é a pontuação do magistrado

$V_{P_{\text {Max }}}$ é o valor padronizado máximo da competência

$\mathrm{VP}_{\text {Juiz }}$ é o valor padronizado do magistrado.

Dessa forma, o magistrado com o maior valor padrão é considerado o mais eficiente e, consequentemente, recebe 30 pontos. Como, de acordo com a metodologia estatística do valor padronizado, 99,72\% dos valores variam em 3 desvios-padrões acima ou abaixo da média, após simulações realizadas, estipulou-se que, a cada unidade de valor padronizado abaixo do $\mathrm{VP}_{\mathrm{Max}^{\prime}}$ o magistrado perde 2 pontos dos 30 possíveis.

Seguindo o exemplo do Juiz A, demonstra-se na Figura 4 o cálculo da final de sua pontuação, levando-se em conta os demais magistrados da competência: 
Figura 4

Cálculo da Pontuação (Juiz A)

\section{Cálculo da Pontuacão (Juiz A):}

$\begin{array}{ll}\begin{array}{l}\text { Juiz A } \\ \text { Juiz B } \\ \text { Juiz C } \\ \text { Juiz D } \\ \text { Juiz E }\end{array} \quad\left[\begin{array}{l}\text { Média da Comp. }=90,8 \% \\ \text { Desvio Padrão }=11,52 \\ \text { Valor padronizado } \\ \left(\frac{\text { eficiência-média }}{D P}\right)\end{array}\right. & \begin{array}{l}\text { Valor Padr. Juiz } A=-0,156 \\ \text { Valor Padr. Juiz } B=0,798 \\ \text { Valor Padr. Juiz C }=0,798 \\ \text { Valor Padr. Juiz D }=-1,632 \\ \text { Valor Padr. Juiz E }=0,190\end{array}\end{array}$

Pontuação: $30-\left(\frac{V P_{M a ́ x i m o}-V P_{J u i z}}{0,5}\right)$

Pontuação na 1ạ Competência (Jan-Fev) $=[(28+25) / 2]=26,5$

Pontuação na 2a Competência (Jan -Fev) $=23$

Pontuação Sugerida (Jan-Fev) $=[(26+23) / 2]=\mathbf{2 4 , 7 5}$

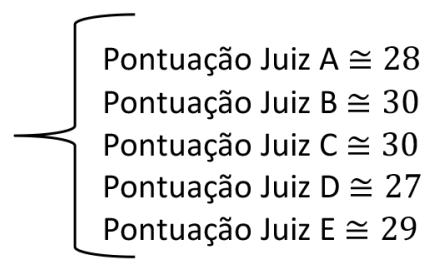

Fonte: Elaborado pelos autores.

Nota-se que no mês de janeiro os juízes B e C alcançaram o maior valor padronizado, recebendo 30 pontos cada um. O Juiz A, por sua vez, obteve uma eficiência abaixo da média e por isso ficou com o valor padronizado negativo (aproximadamente uma unidade abaixo do $\mathrm{VP}_{\mathrm{Max}}$ ), o que fez com que ele perdesse 2 pontos.

Ressalta-se, finalmente, que, se o magistrado tiver atuado em mais de uma competência no período, sua pontuação é calculada dentro de cada uma delas, considerando a respectiva média e desvio padrão, de forma que a pontuação mensal é dada pela média das pontuações obtidas nas diversas competências em que o juiz tiver atuado. A pontuação final do período, por sua vez, é obtida a partir da média das pontuações mensais.

\section{Informações geradas}

O Eficiência.jus apresenta uma interface em que é possível selecionar os magistrados candidatos à promoção. O sistema gera um relatório que traz para cada candidato, além de informações básicas, como mês de referência da promoção, número de meses considerados para análise e número de candidatos, como se vê no exemplo da Tabela 4. 


\section{Tabela 4}

Relatório gerado para a promoção de magistrados

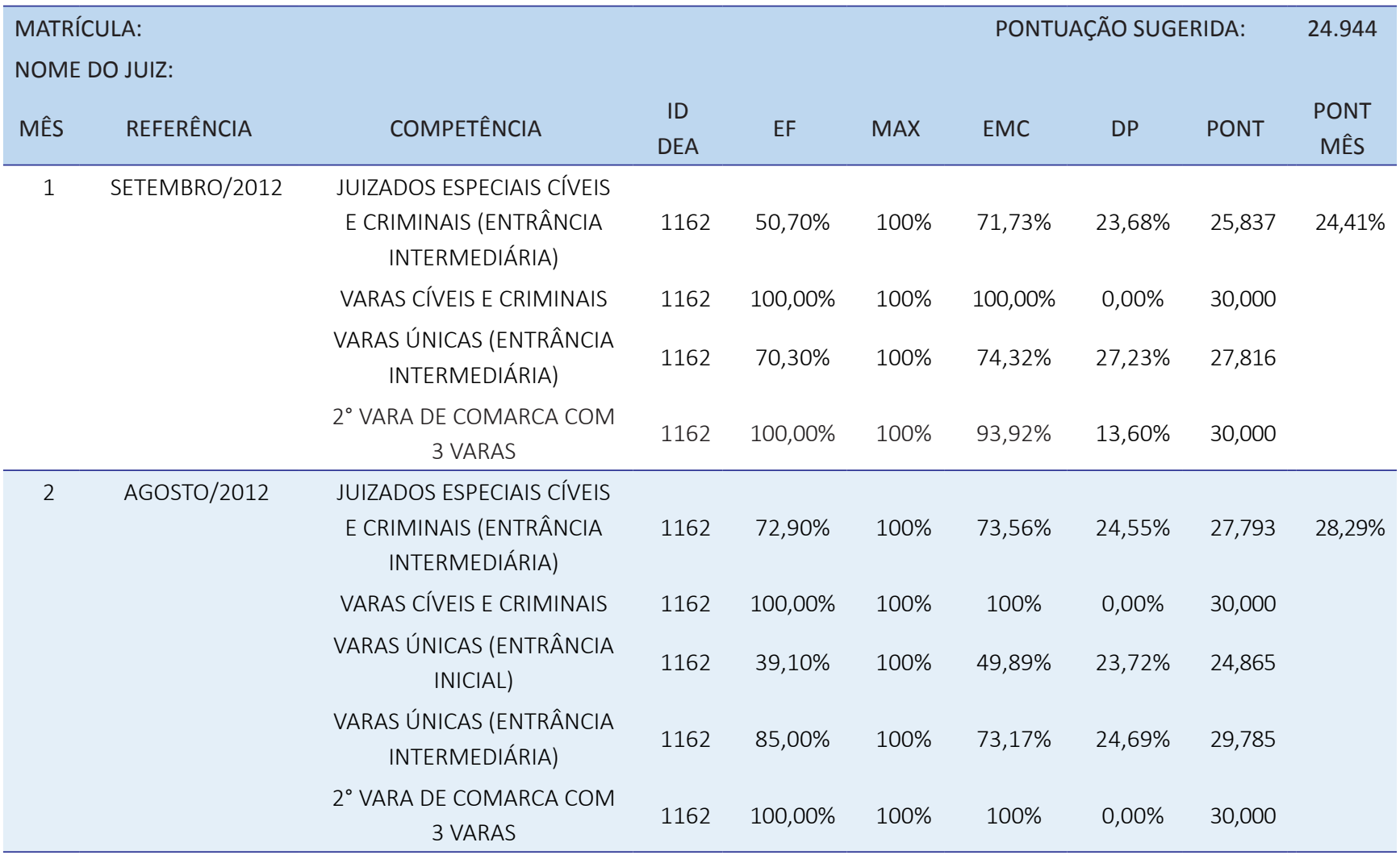

Fonte: Elaborado pelos autores e extraído do Eficiência.Jus.

A Tabela 4 mostra, para cada mês, a eficiência do juiz, a média, o desvio padrão, o mínimo e o máximo de cada competência em que ele prestou serviço, o valor padronizado e a pontuação que, no caso do juiz abordado no exemplo, corresponde à média das pontuações obtidas por competência, bem como a pontuação sugerida pelo sistema, baseada na média das pontuações mensais do período.

\section{ANÁLISE DE EFICIÊNCIA DAS SECRETARIAS DE VARAS}

Para a análise das unidades judiciárias verificou-se, também, a necessidade de agrupamento por competência, nos mesmos moldes utilizados para o cálculo da eficiência dos magistrados. A competência apresenta especificidades próprias, cuja desconsideração, numa comparação geral, certamente geraria conclusões distorcidas ou equivocadas.

As variáveis utilizadas para analisar a eficiência das unidades estão na Quadro 2: 


\section{Quadro 2}

Variáveis para o cálculo de eficiência

\begin{tabular}{|l|l|c|}
\hline \multicolumn{1}{|c|}{ SIGLA } & & DESCRIÇÃO DA VARIÁVEL \\
\hline CNCrim & Casos Não Criminais & INPUT \\
\hline CCrim & Casos Criminais & INPUT \\
\hline PNCrim & Precatórias Não Criminais & INPUT \\
\hline PCrim & Precatórias Criminais & INPUT \\
\hline num_func & No de Funcionários do Quadro Efetivo & INPUT \\
\hline num_colab & No de Colaboradores (terceirizados, estagiários e Comissionados) & INPUT \\
\hline num_comp & No de Computadores & INPUT \\
\hline num_juize & No de juízes & OUTPUT \\
\hline Des & Despachos & OUTPUT \\
\hline Pdev & Precatórias Devolvidas & OUTPUT \\
\hline Sent & Sentenças & OUTPUT \\
\hline Aud & Audiências & OUTPUT \\
\hline Dint & Decisões Interlocutórias & OUTPUT \\
\hline num_Conc & Número de Conciliações Realizadas & OUTPUT \\
\hline TMedProc & Tempo Médio do Processo na Vara & ONT
\end{tabular}

Fonte: TJCE, 2010b.

Para a análise de um período selecionado, o sistema calcula a eficiência mensal da unidade, apresentando, no relatório, a média, a menor e a maior eficiência e a variância e o desvio-padrão das eficiências da competência em cada mês, conforme mostra a Tabela 5:

Tabela 5

Eficiências de varas únicas (entrância inicial), junho e julho de 2011

\begin{tabular}{llc}
\hline & VARAS ÚNICAS (ENTRÂNCIA INICIAL) & \\
\hline \multirow{2}{*}{ JUNHO/2011 } & Médias das Eficiências dos Unidade & $95,82 \%$ \\
& Menor Valor das Eficiências das Unidades & $45,60 \%$ \\
& Maior Valor das Eficiências das Unidades & $100,00 \%$ \\
& Variâncias das Eficiências das Unidades & $2,28 \%$ \\
& Desvio Padrão das Eficiências das Unidades & $15,09 \%$ \\
\hline JULHO/2011 & Médias das Eficiências dos Unidade & $92,22 \%$ \\
& Menor Valor das Eficiências das Unidades & $53,50 \%$ \\
\cline { 2 - 3 } & Maior Valor das Eficiências das Unidades & $100,00 \%$ \\
& Variâncias das Eficiências das Unidades & $2,36 \%$ \\
& Desvio Padrão das Eficiências das Unidades & $15,36 \%$ \\
\hline
\end{tabular}

Fonte: Elaborado pelos autores e extraído do Eficiência.Jus.

Em seguida, mostra-se o gráfico com o ranking das eficiências, com a média sendo mostrada e evidenciando as comarcas que estão acima ou abaixo da média, conforme se verifica no Gráfico 3. Este gráfico demonstra na prática uma das principais 
funções da DEA que consiste na ideia de benchmarking, fazendo com que as unidades eficiências sirvam de referências para as demais unidades (PEÑA, 2008; NOGUEIRA, OLIVEIRA, VASCONCELOS et al., 2012).

\section{Gráfico 3:}

Ranking das eficiências de exemplos de unidades judiciais no período

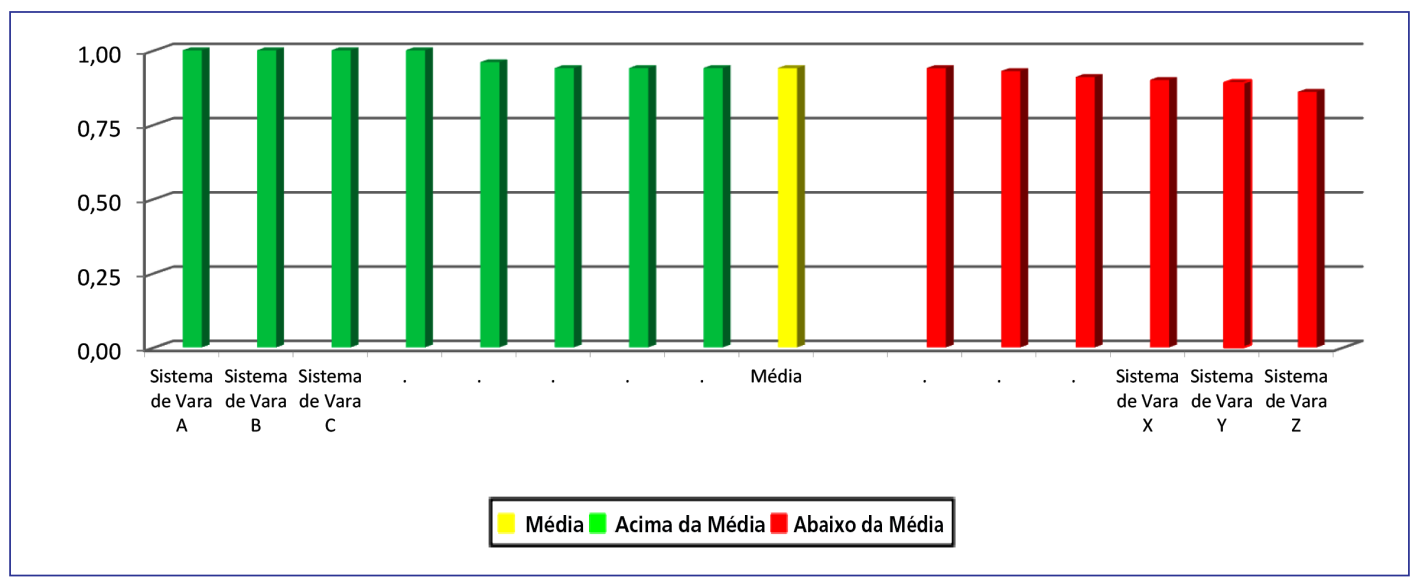

Fonte: Elaborado pelos autores e extraído do Eficiência.Jus.

O sistema apresenta, ainda, o gráfico da evolução da eficiência da competência no período informado, conforme o Gráfico 4:

Gráfico 4

Evolução da eficiência nas varas únicas (entrância inicial), Jun/2011 - Dez/2011

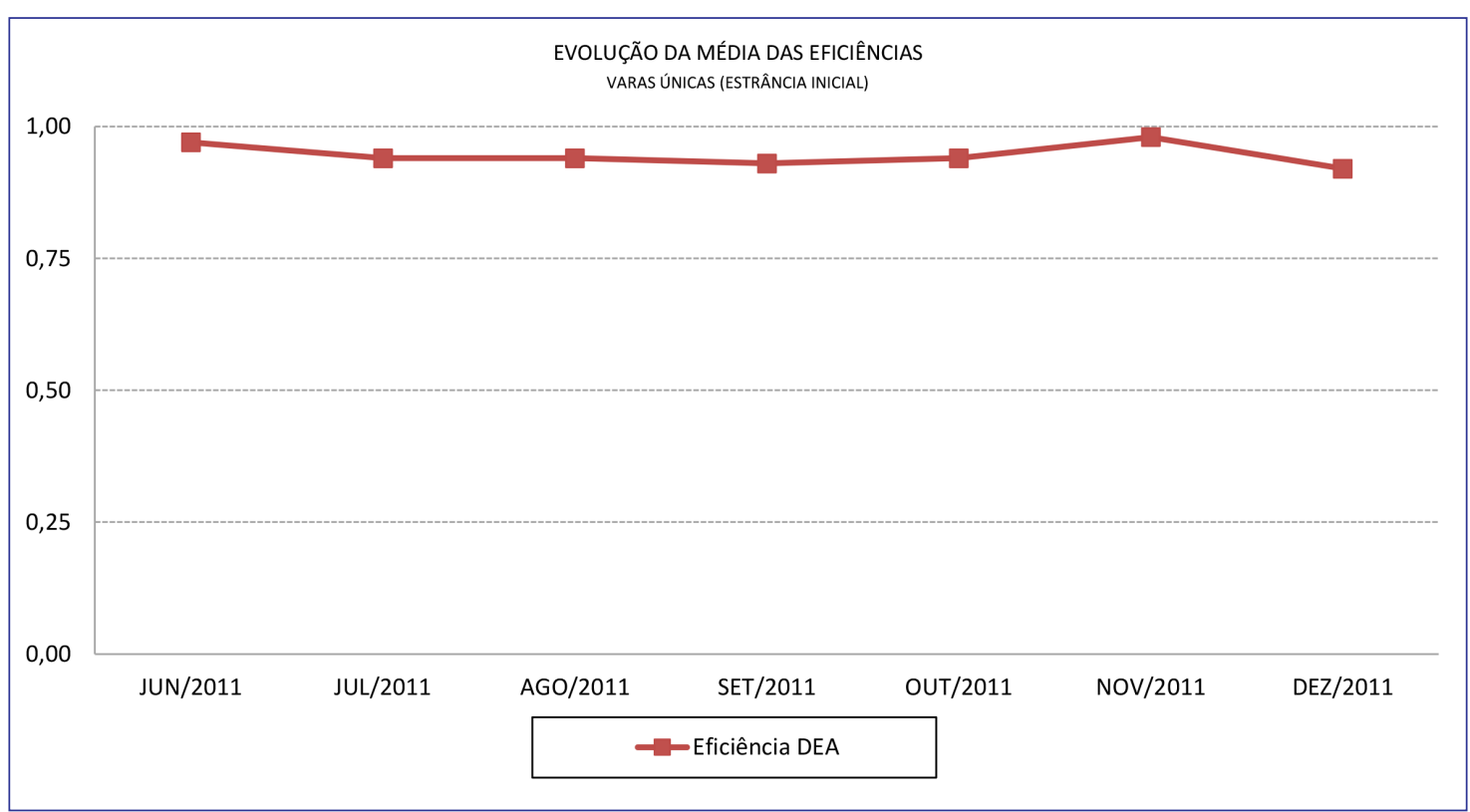

Fonte: Elaborado pelos autores e extraído do Eficiência.Jus.

É possível, também, a visualização dos relatórios individuais de eficiência de cada unidade no período, os quais nos trazem a análise do desempenho da unidade em cada mês do período, conforme apresenta a Tabela 6: 


\section{Tabela 6}

Eficiência de uma unidade no mês de Agosto de 2011

\begin{tabular}{|c|c|c|c|c|c|c|c|}
\hline \multirow[b]{3}{*}{ TIPO } & \multirow[t]{2}{*}{ AGOSTO/2011 } & \multirow[b]{3}{*}{ VALOR } & & & \multicolumn{2}{|c|}{$\begin{array}{r}\text { RANK: } \\
\text { EFICIÊNCIA DEA: }\end{array}$} & \multirow{2}{*}{$\begin{array}{c}12 \\
56,00 \% \\
93,24 \%\end{array}$} \\
\hline & & & \multicolumn{4}{|c|}{ EFICIÊNCIA DEA MÉDIA DA COMPETÊNCIA: } & \\
\hline & VARIÁVEL & & PROJEÇÃO & TIPO & VARIÁVEL & VALOR & PROJEÇÃO \\
\hline (1) & CpCrim & 878 & 239,08 & $(1)$ & CpCrim & 2482 & 856,4 \\
\hline ( 1 ) & numColab & 10 & 10 & $(1)$ & numComp & 26 & 2,76 \\
\hline ( 1$)$ & NumFunc & 16 & 8,06 & (1) & numJuizes & 2 & 1,16 \\
\hline ( 1$)$ & PpCrim & 45 & 8,33 & (1) & PpNCrim & 35 & 6,53 \\
\hline (O) & AudVrim & 3 & 14,23 & ( O ) & AudNCrim & 16 & 28,58 \\
\hline ( O ) & Conc & 0 & 17,1 & ( O ) & DesCrim & 105 & 187,58 \\
\hline ( O ) & DesNCrim & 194 & 346,58 & ( O ) & DIntCrim & 6 & 11,8 \\
\hline ( O ) & DIntNCrim & 3 & 19,41 & ( O ) & PDevCrim & 0 & 0,33 \\
\hline ( O ) & PDevNCrim & 0 & 0,33 & ( O ) & SentCrim & 0 & 15,84 \\
\hline ( O ) & SentNCrim & 15 & 77,43 & ( O ) & Sjur & 0 & 0,79 \\
\hline ( O ) & TBaixCrim & 1 & 25,86 & ( O ) & TBaixNCrim & 33 & 64,33 \\
\hline
\end{tabular}

Fonte: Elaborado pelos autores e extraído do Eficiência.Jus.

A Tabela 6 mostra a eficiência da unidade no mês, a média da competência, a sua posição no ranking e, como forma de direcionar os trabalhos da unidade, a projeção dos valores ótimos que deveriam ser obtidos em cada variável para que a unidade fosse mais eficiente.

Por fim, tem-se o desempenho da unidade por ser avaliado no contexto evolutivo e comparativo, conforme se verifica no Gráfico 5, que mostra a evolução da eficiência da unidade no período em comparação com a média obtida pela competência.

\section{Gráfico 5:}

Média das eficiências nas varas únicas (entrância inicial), Jun/2011 - Dez/2011

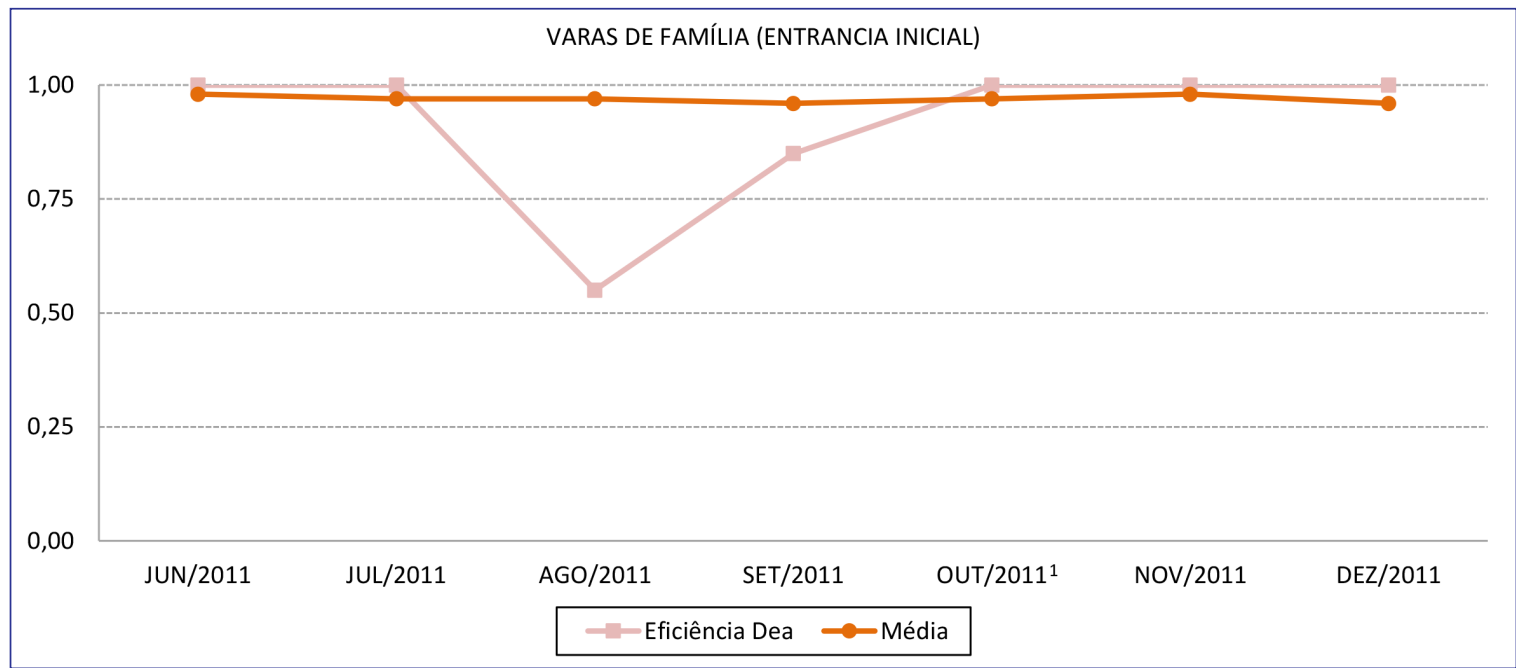

Fonte: Elaborado pelos autores e extraído do Eficiência.Jus. 


\section{CONSIDERAÇÕES FINAIS}

O presente trabalho procurou atender ao objetivo de retratar as principais características do sistema Eficiência.jus como um Sistema de Apoio à Decisão que permite medir a eficiência de unidades judiciárias e de magistrados no TJCE. Ficou evidenciado que o Eficiência.jus vem sendo desenvolvido no intuito de produzir informações estatisticamente tratadas que visem auxiliar a tomada de decisões dos dirigentes do Judiciário cearense e também servir como um apoio objetivo nos processos de promoções das carreiras dos juízes estaduais.

O sistema buscou detalhar as especificidades necessárias para evitar comparações desleais no cálculo das eficiências e, principalmente, no que tange à produtividade de magistrados utilizada para a promoção.

Em meio à caracterização do sistema, é importante que se proceda também a uma discussão focada nas dificuldades gerenciais e culturais encontradas quando de sua concepção e desenvolvimento, como também é necessário que seja dada ênfase às condições organizacionais básicas exigidas para seu funcionamento pleno. O sistema possibilita uma melhor visualização da situação das unidades judiciais, identificando elementos que precisam de aperfeiçoamento para o alcance da eficiência. Portanto, trabalha tanto como a ideia de benchmarking (PEÑA, 2008; NOGUEIRA, OLIVEIRA, VASCONCELOS et al., 2012), bem como a noção de avaliação do desempenho judicial do magistrado (DPJ, 2011), auxiliando com a mensuração critérios objetivos para o processo de promoção na carreira (CNJ, 2010).

Até o momento não se tem conhecimento por parte dos autores de que outro tribunal estadual utilize de procedimentos semelhantes aos adotados pelo TJCE. Tal fato tanto pode ser visto como uma limitação, por não possibilitar comparações de forma e conteúdo, o que poderia ensejar aprimoramentos. Por outro lado, porém, pode ser considerado um fator importante a realização deste estudo como meio de divulgação para um eventual interesse de outros tribunais quanto à adoção dos procedimentos aqui apresentados.

Ressalte-se também o enfoque majoritariamente quantitativo adotado no presente estudo, o que leva, consequentemente, à sugestão da realização de estudos de caráter qualitativo para que se possa aprofundar noutros aspectos de interferência da eficiência de unidades judiciais e de magistrados.

Recomenda-se, por fim, que mais estudos que envolvam a Gestão do Poder Judiciário sejam realizados, o que faria com que a lacuna apontada por Nogueira (2011) seja gradativamente preenchida. 


\section{REFERÊNCIAS}

BEENSTOCK, M.; HAITOVSKY, Y. Does the appointment of judges increase the output of the judiciary? International Review of Law and Economics, v. 24, n. 3, p. 351-369, 2004.

CASTRO, A. S. Indicadores básicos de desempenho da justiça estadual de primeiro grau no Brasil. Texto para discussão, n. 1609. Brasília, IPEAD, 2011.

CEARÁ. Lei no 14.407, de 15 de julho de 2009. Altera e inclui dispositivos na Lei no 12.342, de 28 de julho de 1994, Código de Divisão e Organização Judiciária do Estado do Ceará e dá outras providências. Disponível em: <http://www.al.ce.gov.br/legislativo/legislacao5/ leis2009/14407.htm>. Acesso em: 10 mar. 2013.

CHARNES, A.; COOPER, W. W.; RHODES, E. Measuring the efficiency of decision making units. European Journal of Operational Research, v. 2, n. 6, p. 429-444, 1978.

CNJ - CONSELHO NACIONAL DE JUSTIÇA. Resolução n. 15, de 20 de abril de 2006. Dispõe sobre a regulamentação do Sistema de Estatística do Poder Judiciário, fixa prazos e dá outras providências. 2006. Disponível em: <http://www.cnj.jus.br/images/stories/docs_ cnj/resolucao/rescnj_15.pdf>. Acesso em: 10 mar. 2013.

CNJ - CONSELHO NACIONAL DE JUSTIÇA. Resolução no 106, de 06 de abril de 2010. Dispõe sobre os critérios objetivos para aferição do merecimento para promoção de magistrados e acessos aos Tribunais de 2 o grau. Disponível em: <http://www.cnj.jus.br/images/stories/ docs_cnj/resolucao/rescnj_106.pdf>. Acesso em: 10 mar. 2013.

COOPER, W. W.; SEIFORD, L. M.; TONE, K. Date Envelopment Analysis: A Comprehensive Text with Models, Applications, References and DEA - Solver Software. Second Edition. New York: Springer, 2007.

DPJ - DEPARTAMENTO DE PESQUISAS JUDICIÁRIAS. Avaliação do desempenho judicial: desafios, experiências internacionais e perspectivas. Série CNJ Acadêmico, n. 5. Brasília: CNJ, 2011.

DPJ - DEPARTAMENTO DE PESQUISAS JUDICIÁRIAS. Justiça em Números 2012. Brasília: CNJ, 2012.

DPJ - DEPARTAMENTO DE PESQUISAS JUDICIÁRIAS. Justiça em Números 2013. Brasília: CNJ, 2013.

FOCHEZATTO, A. Análise da eficiência relativa dos tribunais de justiça estadual brasileira utilizando o método DEA. In: Reunión de Estudos Regionales - AECR. 2010, 36. Anais... Badajoz, AECR, 2010.

GOMES, A. O.; GUIMARÃES, T. A. Desempenho no judiciário. Conceituação, estado da arte e agenda de pesquisa. Rev. Adm. Pública, v. 47, n. 2, p. 379-421, mar./abr. 2013.

GORMAN, M.; RUGGIERO, J. Evaluating U. S. judicial district prosecutor performance using DEA: are disadvantaged counties more inefficient? European Journal of Law and Economics, v. 27, n. 3, p. 275-283, 2009.

LEWIN, A. Y.; MOREY, R. C.; COOK, T. J. Evaluating the administrative efficiency of courts. Omega - International Journal of Management Science, v. 10, n. 4, p. 401-411, 1982.
MEIRELES, A. M. R. Uma proposta de SAD para avaliação da eficiência do Poder Judiciário do Estado do Ceará utilizando AED. 2012. $112 \mathrm{f}$. Dissertação (Mestrado em Computação Aplicada) - Universidade Estadual do Ceará; Instituto Federal de Educação, Ciência e Tecnologia do Ceará, Fortaleza, 2012.

MITSOPOULOS, M.; PELAGIDIS, T. Does staffing affect the time to dispose cases in Greek courts? International Review of Law and Economics, v. 27, n. 2, p. 219-244, 2007.

NOGUEIRA, J. M. M. A ausência do Poder Judiciário enquanto objeto de estudo da Administração Pública brasileira. Revista Eletrônica Díke, v. 1, n. 1. p. 1-17, jan./jul. 2011

NOGUEIRA, J. M. M. et al. Estudo exploratório da eficiência dos Tribunais de Justiça estaduais brasileiros usando a análise envoltória de dados (DEA). Rev. Adm. Pública, v. 46, n. 5, p. 1317-1340, set./out. 2012.

PEDRAJA-CHAPARRO, F.; SALINAS-JIMENEZ, J. An assessment of the efficiency of Spanish Courts using DEA. Applied Economics, v. 28, n. 11, p. 1391-1403, 1996.

PEÑA, C. R. Um modelo de avaliação de eficiência da administração pública através do método análise envoltória de dados (DEA). Revista de Administração Contemporânea, v. 1, n. 12, p. 83-106, 2008.

SADEK, M. T. Judiciário: mudanças e reformas. Estudos Avançados, v. 18, n. 51, p. 19-101, 2004.

SVERRE, F. R. F.; KITTELSEN, A. C. Efficiency analysis of Norwegian District Courts. Journal of Productivity Analysis, v. 3, n. 3, p. 277 306, 1992.

TJCE - TRIBUNAL DE JUSTIÇA DO ESTADO DO CEARÁ. Resolução no 18, de 10 de dezembro de 2009. Dispõe sobre a instalação da 5a Vara da Comarca de Caucaia, a especialização de competência das varas da referida comarca e dá outras providências. Disponível em: <http://bdjur.tjce.jus.br/jspui/bitstream/123456789/107/1/ Resolu\%C3\%A7\%C3\%A30\%20n.18\%20-\%202009.pdf>. Acesso em: 10 mar. 2013.

TJCE - TRIBUNAL DE JUSTIÇA DO ESTADO DO CEARÁ. Resolução no 07, de 15 de abril de 2010a. Altera a competência dos juízes de direito da Comarca de Sobral, especializando-a, e modifica a denominação de juízos. Disponível em: <http://bdjur.tjce.jus.br/jspui/ bitstream/123456789/496/1/Resolu\%C3\%A7\%C3\%A30\%20n.7\%20 -\%202010.pdf >. Acesso em: 10 mar. 2013.

TJCE - TRIBUNAL DE JUSTIÇA DO ESTADO DO CEARÁ. Resolução no 10, de 28 de maio de 2010b. Disciplina o provimento dos cargos que indica e dá outras providências. Disponível em: <http://bdjur.tjce.jus. br/jspui/bitstream/123456789/499/1/Resolu\%C3\%A7\%C3\%A3०\%20 n.10\%20-\%202010.pdf>. Acesso em: 10 mar. 2013.

TJCE - TRIBUNAL DE JUSTIÇA DO ESTADO DO CEARÁ. Resolução no 12, de 05 de agosto de 2010c. Altera a competência dos juízes de direito da Comarca de Juazeiro do Norte, especializando-a, e modifica 
a denominação de juízos. Disponível em: <http://bdjur.tjce.jus.br/ jspui/bitstream/123456789/501/1/Resolu\%C3\%A7\%C3\%A30\%20 n.12\%20-\%202010.pdf >. Acesso em: 10 mar. 2013.

TJCE - TRIBUNAL DE JUSTIÇA DO ESTADO DO CEARÁ. Resolução no 05, de 16 de junho de 2011. Altera a competência dos Juízes de Direito da comarca de Maracanaú, especializando-a, modifica a denominação de juízos e dá outras providências. Disponível em: <http://www.tjce. jus.br/includes/mostraAnexo.asp?san=46>. Acesso em: 10 mar. 2013.
YEUNG, L. L. Além dos "achismos", do senso comum e das evidências anedóticas: uma análise econômica do judiciário brasileiro. 2010. 241 f. Tese (Doutorado em Economia de Empresas) - Escola de Economia de São Paulo da Fundação Getulio Vargas, São Paulo, 2010.

YEUNG, L. L.; AZEVEDO, P. F. Measuring efficiency of Brazilian courts with data envelopment analysis (DEA). IMA Journal of Management Mathematics, v. 22, n. 4, p. 343-356, 2011.

Leonel Gois Lima Oliveira

Doutor em Administração pela Escola Brasileira de Administração Pública e de Empresas da Fundação Getulio Vargas (EBAPE/FGV); Professor da Escola Superior de Magistratura do Estado do Ceará (Esmec).E-mail: leonelgois@tjce.jus.br

José Marcelo Maia Nogueira

Mestre em Administração Pública e Governo pela Escola de Administração de Empresas de São Paulo da Fundação Getulio Vargas (EAESP/FGV); Professor da Escola Superior de Magistratura do Estado do Ceará (ESMEC).E-mail: marcelomaia@tjce.jus.br

Kátia Michelle Matos de Oliveira

Mestre em Logística e Pesquisa Operacional pela Universidade Federal do Ceará (Geslog/UFC); Diretora de Estatísticas do Tribunal de Justiça do Estado do Ceará (TJCE).E-mail: michellematos@tjce.jus.br

Sérgio Mendes de Oliveira Filho

Mestre em Economia pela Universidade Federal do Ceará (Caen/UFC); Professor da Escola Superior de Magistratura do Estado do Ceará (Esmec).

E-mail: sergio.filho@tjce.jus.br 